\title{
Willingness to pay for cataract surgery is much lower than actual costs in Zamfara State, northern Nigeria
}

Nazaradden Ibrahim ${ }^{1}$

Jacqueline Ramke ${ }^{2}$

Francisco Pozo-Martin ${ }^{3}$

Clare E Gilbert ${ }^{4}$

1. Zamfara State Eye Care Programme, Ministry of Health, Gusau, Nigeria

2. Department of Epidemiology and Biostatistics, Faculty of Medicine and Health Sciences, University of Auckland, Auckland, New Zealand

3. Department of Global Health and Development, London School of Hygiene and Tropical Medicine, London, United Kingdom

4. International Centre for Eye Health, Clinical Research Unit, Department of Infectious \& Tropical Diseases, London School of Hygiene and Tropical Medicine, London, United Kingdom

Corresponding Author: Jacqueline Ramke

jramke@gmail.com

Dept of Epidemiology \& Biostatistics, Faculty of Medical and Health Sciences, The University of Auckland.

Private Bag 92019 Auckland Mail Centre

Auckland 1142, New Zealand

Conflict of interest: None of the authors have any proprietary interests or conflicts of interest related to this submission.

Financial support: The study was funded by the Commonwealth Scholarship Scheme, Sightsavers UK and Hooper Scholarship. None of the funders contributed to the design of the study, data collection and analysis, interpretation of data or in writing the script, or the decision to submit the publication.

Running head: Willingness to pay for cataract surgery in Nigeria

This submission has not been published anywhere previously and it is not simultaneously being considered for any other publication. 


\section{ABSTRACT}

Purpose: Direct medical and non-medical costs incurred by those undergoing subsidised cataract surgery at Gusau eye clinic, Zamfara state were recently determined. The aim of this study was to assess the willingness to pay for cataract surgery among adults with severe visual impairment or blindness from cataract in rural Zamfara, and to compare this to actual costs.

Methods: In three rural villages served by Gusau eye clinic, key informants helped identify 80 adults with bilateral severe visual impairment or blindness $(<6 / 60)$, with cataract being the cause in at least one eye. The median amount participants were willing to pay for cataract surgery was determined. The proportion willing to pay actual costs of the i) subsidised surgical fee (US\$18.5), ii) average non-medical expenses (US\$25.2), and iii) average total expenses (US\$51.2) at Gusau eye clinic were calculated. Where participants would seek funds for surgery was determined.

Results: Among 80 participants (38\% women), most ( $n=73,91 \%)$ were willing to pay something, ranging from < US\$1-US\$186 (median US\$18.5, IQR 6.2-31.1). Approximately half of participants ( $n=41)$ were willing to pay US\$18.5 (78\% men), one-third $(n=26)$ were willing to pay US $\$ 25.2$ (77\% men); and $11 \%(n=9)$ were willing to pay US\$51.2 (all men). Only 6 participants (8\%) already had the money to pay; one quarter $(n=20)$ would need to sell possessions to raise the funds.

Conclusion: Willingness to pay for cataract surgery among adults with operable cataract in rural Zamfara state is far lower than current costs of undergoing surgery. People who were widowedmost of whom were women—were willing to pay least. Further financial support is required for cataract surgery to be universally accessible.

Keywords: Cataract surgery, health care financing, willingness to pay, Universal Health Coverage, equity 


\section{INTRODUCTION}

The goal of the World Health Organization's (WHO) global eye care plan is to reduce avoidable blindness and visual impairment. ${ }^{1}$ Cataract is the leading cause of blindness and a major cause of visual impairment globally. ${ }^{2}$ Therefore, to achieve WHO's global goal, strategies must be implemented to reduce the prevalence of visual loss due to cataract and its unequal distribution. These strategies will include improving the quantity, quality and accessibility of cataract services, especially for population subgroups historically disadvantaged.

In Nigeria, a recent national survey estimated that half a million Nigerians will be blind from cataract by 2020 , and that older people, women, those living in poorer households and those not living in the South-West geopolitical zone are more likely to be cataract blind. ${ }^{3,4}$ Access to cataract surgery is low in Nigeria, with only $38.3 \%$ of those needing surgery accessing it, and women, rural dwellers, the illiterate and those aged $\geq 70$ years having lower cataract surgical coverage than men, urban dwellers, the literate and those younger than 70 years respectively. ${ }^{5}$ Cost was the primary barrier to care for more than one-third (36.0\%) of those who were cataract blind. ${ }^{5}$ Barriers did not differ by age or gender, but rural dwellers were more likely to experience cost barriers compared to their urban counterparts. ${ }^{5}$

Zamfara state in northern Nigeria has a population of 3.6 million, $80 \%$ of whom live in rural areas, and $70 \%$ of whom live on less than United States dollar (US\$) $1 /$ day. ${ }^{6,7}$ Gusau eye clinic is one of two government clinics in Zamfara that provide cataract surgical services, and in 2013 Gusau's three ophthalmologists provided 2,368 cataract surgeries; $46 \%$ of surgical patients were women. Outreach cataract screening is infrequent, so generally people must present to the eye clinic via bad roads, and travel for up to 4 hours. In 2013 cataract surgery was subsidised by an international non-governmental organisation so patients had to contribute Nigerian Nara (N) 3,000 (US\$18.5) towards the cost of surgery, in addition to paying all other non-medical costs. A complementary study to this one found the median direct cost for 104 people undergoing surgery at Gusau eye clinic in 2013 was US\$51.2 (N8,245), which included US\$25.2 (N4,050) for direct non-medical costs to attend for surgery as well as pre- and post-operative care such as travel, meals and 
accommodation for the patient and their escort. ${ }^{8}$ Costs for those living further than 50 kilometres $(\mathrm{km})$ from the hospital (US\$84), were more than twice as high as for those living within $50 \mathrm{~km}$ (US\$40). ${ }^{8}$ The same study found that $14 \%$ of women and $8 \%$ of men had to sell assets to raise the funds for surgery. ${ }^{8}$

In addition to quantifying the costs of those who had accessed surgery in Zamfara state, we wanted to understand the level of subsidisation required to make cataract surgery affordable for rural dwellers who needed surgery but had not accessed it. The aims of the study presented here were to assess the willingness to pay for cataract surgery among rural dwellers with cataract causing visual acuity worse than 6/60, and to compare this to the costs of undergoing surgery in 2013 in Zamfara state, northern Nigeria.

\section{MATERIALS AND METHODS}

\section{Study Design}

This study was a community-based survey of adults who had presenting visual acuity of worse than $6 / 60$ in both eyes with cataract being the main cause in at least one eye. A sample size of 80 people was considered sufficient to be able to compare willingness to pay with actual costs of surgery, and to compare findings by key sociodemographic variables. Three villages between 25$100 \mathrm{~km}$ of Gusau eye clinic were purposely selected from which to recruit participants (one in each of Anka, Bukkuyum and Maru Local Government Area, total population of all ages approximately 25,000).

Following an initial visit to each village when the purpose of the study was explained, local key informants, usually village elders, were asked to identify adults who had lived in the village for at least 6 months who seemed to be blind. A few days later the study team, comprising two ophthalmic nurses and an ophthalmologist (NI), visited the villages. The key informant led the team to the relevant households where the ophthalmic nurse measured visual acuity of potential participants 
using the tumbling E-chart. Using a pen torch, the ophthalmologist assessed those with visual acuity worse than $6 / 60$ in both eyes for the presence of cataract in at least one eye. Those who were eligible were invited to participate. The purpose of the study was explained and informed consent obtained.

\section{Data collection}

Two ophthalmic nurses participated in two days of training which included interview skills, and refining the questionnaire by administering it to non-study individuals. These two nurses then collected sociodemographic data from participants using a structured questionnaire in the local language (Hausa) that matched the data collected in the hospital study ${ }^{8}$ to allow comparison (see below). Data collected included demographic data i.e. age, sex, marital status, size of household, relationship to household head and distance to hospital; and socioeconomic data i.e. ownership of durable household materials (e.g. radio, television, mobile phone), and how they ranked their household wealth relative to other households in the community (higher than average /average /lower than average).

To establish willingness to pay, a clear and understandable description of the scenario was provided. ${ }^{9}$ Participants were informed that cataract was the cause of their vision loss, that surgery was the only method of treatment to restore their sight, and they would need to attend Gusau eye clinic for an initial assessment visit, attend for surgery a few weeks later, and a post-operative visit at two weeks. The willingness to pay question was phrased: "Now that you are aware of the cause of your problem and surgery is the only method of treatment, how much would you be willing to pay to undergo surgery?" Finally, participants were asked how they would obtain the funds to pay for surgery. 


\section{Data Analysis}

Data were entered into a Microsoft access database and transferred into STATA 13.0 (StataCorp LP, TX) for analysis. Data were converted from Nigerian Naira to US\$ at the exchange rate at the time of the study (N161=US\$1) and results are reported using US\$.

Outcome variables were willingness to pay for surgery and how funds to pay for surgery would be obtained. Explanatory variables were age, sex, marital status (married vs widowed), distance to hospital ( $<50 \mathrm{~km}$ vs $\geq 50 \mathrm{~km}$ ), size of household, relationship to household head (head vs wife vs son/daughter vs other), self-assessed household socioeconomic status rank (high vs average vs low), and ownership of assets (none vs one or more). We used the two-sample t-test or chi-squared test, $\chi^{2}$ to assess whether women and men differed in age, marital status or being household head.

The willingness to pay data were not normally distributed, so median and inter-quartile ranges (IQR) were calculated for the subgroups for each explanatory variable, and the Kruskall-Wallis nonparametric test was used to test for a difference in willingness to pay between subgroups. Significant levels are reported at $p<0.05$.

Among subgroups we calculated the proportion willing to pay i) less than the current surgical fee at Gusau eye clinic (i.e. US\$18.5), ii) equal to or greater than the current surgical fee, iii) equal to or greater than the average direct non-medical costs from the earlier analysis (i.e. US\$25.2) and iv) equal to or greater than the total direct costs (i.e. US\$51.2) of cataract surgery ${ }^{8}$. Finally, the anticipated method by which funding would be obtained was calculated across population subgroups. We assessed the statistical significance of the difference between subgroups in willingness to pay and how funds would be obtained using the chi-squared test.

\section{Ethical approval}

Ethical approval was obtained from ethics committees of the London School of Hygiene \& Tropical Medicine and the Ministry of Health, Zamfara State Nigeria. Written informed consent was obtained from all participants. The head of the household or someone assigned by them was invited to stay 
with the participant during the interview. All participants were referred to Gusau eye clinic for subsidised surgery.

\section{RESULTS}

Eighty people were recruited across the three villages; $38 \%$ were women $(n=30), 76 \%$ were married $(n=61)$ and $91 \%(n=73)$ were over 60 years old (Table 1). There was no difference in the mean age of men (70.9 years, standard deviation [SD] 11.0 years), and women (69.5 years SD 9.7) $(t(78)=0.55, p=0.58)$. Women $(n=16,53 \%)$ were more likely to be widowed than men $(n=3,6 \%$; $\left.\chi^{2}=23.2, p<0.001\right)$. Men $(n=43,93 \%)$ were more likely to be head of the household than women $(n=3,10 \%)\left(\chi^{2}=44.3, p<0.001\right)$.

Willingness to pay for surgery Most participants ( $n=73,91 \%)$ were willing to pay something for cataract surgery, ranging from US\$0.6 to US\$186, with a median and IQR of US\$18.5 (6.2-31.1). Men, those who were married, those from larger households ( $\geq 7$ people), and those who were household heads were willing to pay more than women, those who were widows, those from smaller households and those who were not household heads respectively (Table 2). The subgroup willing to pay least for surgery was widows (median US\$9.3, IQR 6.2-12.4).

Approximately half of the participants ( $n=41,51 \%)$ were willing to pay at least the current subsidised surgery fee (US\$18.5), 26 (33\%) were willing to pay an amount that would cover non-medical costs (US\$25.2) and 9 (11\%) were willing to pay an amount that would cover total costs (US\$51.2, Table 3). Men, those who were married and those from larger households were more likely than women, widows and those from smaller households to be willing to pay at least US\$18.5. There were no differences between subgroups in willingness to pay at least US\$25.2. The nine participants willing to pay at least US\$51.2 for their surgery were all married men who were household heads (Table 3). 


\section{Fund-raising for surgery}

Very few participants $(n=6,8 \%)$ reported having enough money to pay for surgery (Table 4). Over half of all participants ( $n=50,64 \%$ ) said they would ask their family or friends to pay on their behalf, while one quarter ( $n=20,26 \%)$ would need to sell possessions. The only statistically significant difference between subgroups was that those from smaller households were more likely to ask their family or friends for the funds than those from larger households (Table 4).

\section{DISCUSSION}

In this study in rural Zamfara state, northern Nigeria the median amount 80 adults with cataract causing visual acuity worse than $6 / 60$, were willing to pay for cataract surgery was US $\$ 18.5$ (IQR 6.2-31.1). This amount matches the subsidised price for cataract surgery at the Gusau eye clinic, but falls short of the direct non-medical costs (US\$25.2) and total costs (US\$51.2) incurred by patients who had recently undergone cataract surgery at the clinic. ${ }^{8}$ There have been very few studies on willingness to pay for cataract surgery, but in rural settings of countries as diverse as China, ${ }^{10} \mathrm{Nepal},{ }^{11}$ and Tanzania,,${ }^{12}$ as with our study, the amount most people were willing to pay was considerably less than the actual cost of undergoing treatment. In Zamfara, even if all direct medical costs were paid from other sources, only one-third of participants were willing to pay an amount that covered non-medical costs such as travel and accommodation.

Health financing from user-fees is considered the least equitable form of financing as user-fees absorb a larger proportion of the income of poor households than rich households. ${ }^{13,14}$ More than a decade ago, Member States at the World Health Assembly committed to develop their health financing systems so that all people have access to services and do not suffer financial hardship in paying for them. ${ }^{15}$ This was reinforced in WHO's 2010 World Health Report which recommended countries reduce reliance on user-fees to improve equity of access. ${ }^{13}$ Financial protection was included as a pillar of the Universal Health Coverage initiative (target 3.8 of the Sustainable 
Development Goals). ${ }^{16}$ Underpinning financial protection is the use of prepayment schemes such as insurance. ${ }^{13}$

However, Nigeria has a long way to go to attain universal coverage. For example, cataract surgery is included in the national health insurance package, but only a small portion of the population is insured. By 2015 fewer than eight million people had enrolled in the National Health Insurance Scheme, meaning less than $1 \%$ of health spending in Nigeria is covered by insurance, compared to more than $70 \%$ generated from user-fees. ${ }^{17}$ In addition, those with insurance tend to be employed in the formal sector, so if alternative financial support is not available to the uninsured, inequity in access to cataract services may increase.

In Zamfara, more vulnerable subgroups of the population are most in need of financial support for cataract surgery. In this study the widowed, most of whom were women (94\%), were the subgroup willing to pay the least for cataract surgery (US\$9.3, IQR 6.2-12.4). Recently the non-governmental organisation removed the surgical fee subsidy, and the cost increased from US\$18.5 to US\$62.1 $(\mathrm{N} 10,000)$. Consequently, it is likely that access by women has reduced even further.

Research into how people find the money to pay for cataract services is very limited. Two-thirds of our sample would ask family or friends to pay, and this reliance on family members is evident elsewhere. For example, in a study in rural China, $70 \%$ of surgeries were paid for by the patient's son or daughter, ${ }^{18}$ while in Tanzania the elderly were reluctant to ask their children for assistance to pay for cataract surgery if the household had experienced other recent health expenses, or if the harvest had been poor. ${ }^{19}$ In our study a quarter of participants would need to sell possessions to raise funds to undergo cataract surgery, which is a higher proportion than the $14 \%$ of women and $8 \%$ of men who had recently undergone surgery at Gusau eye clinic. ${ }^{8}$ These findings support the view that user-fees for health care can create financial hardship or impoverishment. ${ }^{13}$

Cost is one of the most commonly stated barriers to accessing cataract surgery, ${ }^{20}$ so reducing or eliminating user-fees is essential, but in isolation from other strategies is likely insufficient to reduce 
inequity in cataract outcomes. ${ }^{21,22}$ For example, studies from Kenya, Philippines, Bangladesh, ${ }^{21}$ Paraguay ${ }^{23}$ and Tanzania ${ }^{24}$ showed that offering free cataract surgery did not result in higher uptake of surgery among those who were blind or visually impaired from cataract, despite cost being reported as their main barrier to surgery. In addition, in two separate cluster randomised trials in rural China, the uptake of free cataract surgery was only $20-30 \% .{ }^{25,26}$

These findings highlight the need for more qualitative research to capture the nuances of household decision making and health-seeking behaviour, ${ }^{19,27}$ particularly given the context of an aging population and increasing dependency ratios. For example, analysis from the Global Burden of Disease Study, in which blind people were ranked amongst the most dependent, compared the number of dependent people of all ages to the number of people of working age (the dependency ratio). ${ }^{28}$ In all regions the dependency ratio is predicted to increase between 2000 and 2050 , reaching $14 \%$ in China, $12 \%$ in India and $11 \%$ in sub-Saharan Africa by $2050 .{ }^{28}$ The implication of increasing dependency is that those of working age will face a greater burden in caring for their dependents, placing competing demands on their limited resources for eye care. Further research is also needed to assess the impact of different financing mechanisms on equity in access to cataract surgery and how negative impacts on equity of access might be mitigated. ${ }^{29}$

Our analysis must be interpreted in the context of a number of limitations. First, the mostly male key informants nominated more men with vision loss than women, despite the higher prevalence of cataract blindness among women in Nigeria. ${ }^{3}$ Given the higher willingness to pay among men, our overall result is likely to be an overestimate. This potential selection bias also suggests any future use of key informants in this setting would benefit from additional gender-sensitivity training and monitoring to improve identification of eligible women.

Second, despite collecting data on a broad range of asset categories drawn from Nigeria's latest Demographic and Health Survey, ownership of most assets was very similar among the sample so we were unable to construct asset indices using principal component analysis. ${ }^{30}$ This is perhaps unsurprising given the close association between cataract blindness and poverty. ${ }^{4,31}$ Our 
socioeconomically homogeneous sample meant we did not detect differences in willingness to pay by asset ownership or self-rated wealth.

Third, as in all willingness to pay studies, responses are hypothetical, and may overestimate actual willingness to pay. ${ }^{32}$ An assessment of hypothetical willingness to pay a particular price for spectacles in Timor-Leste had good predictive value of actual willingness to pay, ${ }^{33}$ but to our knowledge verification of actual willingness to pay for cataract surgery has not been undertaken. Regardless, if the amounts identified in this study are overestimated, the gaps to actual costs are even greater, increasing the level of financial support required by the socially disadvantaged.

To our knowledge this is the first assessment of willingness to pay for cataract surgery in Nigeria. We have identified a large gap between the current direct costs of cataract surgery and what rural people with vision loss from cataract are willing to pay, with the largest gaps experienced by the widowed, most of whom were women. Improving access to cataract surgery for the most vulnerable will require a comprehensive response-removal of financial barriers is an essential component of this response, and will need to extend beyond the surgical fee to also include outpatient consultations and non-medical expenses. 


\section{References}

1. World Health Organization. Universal Eye Health: A global action plan 2014-2019. Geneva: World Health Organization, 2013.

2. Flaxman SR, Bourne RR, Resnikoff S, et al. Global causes of blindness and distance vision impairment 1990-2020: a systematic review and meta-analysis. Lancet Global Health [DOI: dx.doi.org/10.1016/S2214-109X(17)30393-5.

3. Abdull MM, Sivasubramaniam S, Murthy GVS, et al. Causes of blindness and visual impairment in Nigeria: The Nigeria National Blindness and Visual Impairment Survey. Invest Ophthalmol Vis Sci. 2009;50(9):4114-4120.

4. Tafida A, Kyari F, Abdull M, et al. Poverty and blindness in Nigeria: results from the national survey of blindness and visual impairment. Ophthalmic Epidemiol. 2015;22(5):333-341.

5. Abubakar T, Gudlavalleti MV, Sivasubramaniam S, et al. Coverage of hospital-based cataract surgery and barriers to the uptake of surgery among cataract blind persons in Nigeria: The Nigeria National Blindness and Visual Impairment Survey. Ophthalmic Epidemiol. 2012;19(2):58-66.

6. National Bureau of Statistics. Annual Abstract of Statistics. Abuja, Nigeria: National Bureau of Statistics, 2012.

7. National Bureau of Statistics. Nigeria Poverty Profile 2010. Abuja, Nigeria: National Bureau of Statistics, 2012.

8. Ibrahim N, Pozo-Martin F, Gilbert C. Direct non-medical costs double the total direct costs to patients undergoing cataract surgery in Zamfara state, Northern Nigeria: a case series. BMC Health Serv Res. 2015;15(1):163.

9. Olsen JA, Smith RD. Theory versus practice: a review of 'willingness-to-pay' in health and health care. Health Econ 2001;10(1):39-52.

10. He M, Chan V, Baruwa E, et al. Willingness to pay for cataract surgery in rural Southern China. Ophthalmology. 2007;114(3):411-416.

11. Shrestha M, Thakur J, Gurung C, et al. Willingness to pay for cataract surgery in Kathmandu valley. Br J Ophthalmol. 2004;88(3):319-320.

12. Lewallen $S$, Geneau R, Mahande $M$, et al. Willingness to pay for cataract surgery in two regions of Tanzania. Br J Ophthalmol. 2006;90(1):11-13.

13. World Health Organization. The World Health Report 2010. Health systems financing: the path to universal coverage. Geneva: World Health Organization, 2010.

14. Wagstaff A. Economics, health and development: some ethical dilemmas facing the World Bank and the international community. J Med Ethics. 2001;27(4):262-267.

15. World Health Assembly. Sustainable health financing, universal coverage and social health insurance. Resolution WHA 58.33. Geneva: Fifty-eighth World Health Assembly, 2005.

16. United Nations General Assembly. Transforming our world: the 2030 Agenda for Sustainable Development. Seventieth United Nations General Assembly, New York, 15 September 2015-13 September 2016. New York: United Nations, 2015.

17. GBD Health Financing Collaborator Network. Evolution and patterns of global health financing 1995-2014: development assistance for health, and government, prepaid private, and outof-pocket health spending in 184 countries. Lancet. 2017;389(10083):1981-2004.

18. Congdon N, Rao SK, Choi K, et al. Sources of patient knowledge and financing of cataract surgery in rural China: the Sanrao Study of Cataract Outcomes and Up-Take of Services (SCOUTS), Report 6. Br J Ophthalmol. 2008;92(5):604-608.

19. Geneau R, Lewallen S, Bronsard A, et al. The social and family dynamics behind the uptake of cataract surgery: findings from Kilimanjaro region, Tanzania. $\mathrm{Br} \mathrm{J}$ Ophthalmol. 2005;89(11):1399-1402.

20. Aboobaker S, Courtright P. Barriers to cataract surgery in Africa: A systematic review. Middle East Afr J Ophthalmol. 2016;23(1):145. 
21. Syed A, Polack S, Eusebio C, et al. Predictors of attendance and barriers to cataract surgery in Kenya, Bangladesh and the Philippines. Disabil Rehabil. 2013;35(19):1660-1667.

22. Lewallen S. Poverty and cataract—a deeper look at a complex issue. PloS Med. 2008;5(12):e245.

23. Burga HG, Hinds $\mathrm{CN}$, Lansingh VC, et al. Is the cost the primary barrier for cataract surgery in Paraguay? Arq Bras Oftalmol. 2014;77(3):164-167.

24. Kessy JP, Lewallen S. Poverty as a barrier to accessing cataract surgery: a study from Tanzania. Br J Ophthalmol. 2007;91(9):1114-1116.

25. Liu T, Congdon N, Yan X, et al. A randomized, controlled trial of an intervention promoting cataract surgery acceptance in rural China: the Guangzhou Uptake of Surgery Trial (GUSTO). Invest Ophthalmol Vis Sci. 2012;53(9):5271-5278.

26. Zhang XJ, Liang YB, Liu YP, et al. Implementation of a free cataract surgery program in rural China: a community-based randomized interventional study. Ophthalmology. 2013;120(2):260-265.

27. Rotchford A, Rotchford K, Mthethwa L, et al. Reasons for poor cataract surgery uptake-a qualitative study in rural South Africa. Trop Med Int Health. 2002;7(3):288-292.

28. Harwood RH, Sayer AA, Hirschfeld M. Current and future worldwide prevalence of dependency, its relationship to total population, and dependency ratios. Bull World Health Organ. 2004;82(4):251-258.

29. Ramke J, Zwi AB, Palagyi A, et al. Equity and blindness: closing evidence gaps to support universal eye health. Ophthalmic Epidemiol. 2015;22(5):297-307.

30. Rutstein SO, Johnson K. The DHS wealth index (DHS Comparative Reports No.6). Calverton, MD: ORC Macro, 2004.

31. Kuper H, Polack S, Eusebio C, et al. A case-control study to assess the relationship between poverty and visual impairment from cataract in Kenya, the Philippines, and Bangladesh. PloS Med. 2008;5(12):e244.

32. Onwujekwe O, Hanson K, Fox-Rushby J. Do divergences between stated and actual willingness to pay signify the existence of bias in contingent valuation surveys? Soc Sci Med. 2005;60(3):525-536.

33. Ramke J, Palagyi A, du Toit R, et al. Stated and actual willingness to pay for spectacles in Timor-Leste. Ophthalmic Epidemiol. 2009;16(4):224-230. 
Table 1: Demographic distribution of study participants, Zamfara state, northern Nigeria 2013

\begin{tabular}{|c|c|c|c|}
\hline \multicolumn{2}{|c|}{ Sociodemographic factors } & \multicolumn{2}{|c|}{$\begin{array}{l}\text { Cataract blind or severe } \\
\text { visually impaired } \\
\text { n/80 (\%) }\end{array}$} \\
\hline Age group (years) & $\begin{array}{l}40-49 \\
50-59 \\
60-69 \\
70 \text { and above }\end{array}$ & $\begin{array}{r}2 \\
5 \\
21 \\
52\end{array}$ & $\begin{array}{l}(2.5) \\
(6.3) \\
(26.3) \\
(65.0)\end{array}$ \\
\hline Gender & $\begin{array}{l}\text { Men } \\
\text { Women }\end{array}$ & $\begin{array}{l}50 \\
30\end{array}$ & $\begin{array}{l}(62.5) \\
(37.5)\end{array}$ \\
\hline Marital status & $\begin{array}{l}\text { Married } \\
\text { Widowed }\end{array}$ & $\begin{array}{l}61 \\
19\end{array}$ & $\begin{array}{l}(76.3) \\
(23.8)\end{array}$ \\
\hline $\begin{array}{l}\text { Distance to hospital } \\
(\mathrm{km})\end{array}$ & $\begin{array}{l}<50 \\
\geq 50\end{array}$ & $\begin{array}{l}25 \\
55\end{array}$ & $\begin{array}{l}(31.3) \\
(68.7)\end{array}$ \\
\hline $\begin{array}{l}\text { Size of household } \\
\text { (number of people) }\end{array}$ & $\begin{array}{l}1-3 \\
4-6 \\
7-9 \\
10 \text { and above }\end{array}$ & $\begin{array}{r}15 \\
12 \\
8 \\
45\end{array}$ & $\begin{array}{l}(18.8) \\
(15.0) \\
(10.0) \\
(56.3)\end{array}$ \\
\hline $\begin{array}{l}\text { Relationship to } \\
\text { household head }\end{array}$ & $\begin{array}{l}\text { Head } \\
\text { Wife } \\
\text { Son/daughter } \\
\text { Other }\end{array}$ & $\begin{array}{r}46 \\
14 \\
7 \\
13\end{array}$ & $\begin{array}{l}(57.5) \\
(17.5) \\
(8.8) \\
(16.3)\end{array}$ \\
\hline $\begin{array}{l}\text { Household } \\
\text { socioeconomic } \\
\text { status rank }\end{array}$ & $\begin{array}{l}\text { High } \\
\text { Average } \\
\text { Low }\end{array}$ & $\begin{array}{r}1 \\
13 \\
66\end{array}$ & $\begin{array}{l}(1.3) \\
(16.3) \\
(82.5)\end{array}$ \\
\hline Number of assets & $\begin{array}{l}1 \text { or more } \\
\text { None }\end{array}$ & $\begin{array}{l}44 \\
36\end{array}$ & $\begin{array}{l}(55.0) \\
(45.0)\end{array}$ \\
\hline
\end{tabular}


Table 2: Willingness to pay for cataract surgery by sociodemographic factors among 80 people with cataract blindness or severe visual impairment, Zamfara State, northern Nigeria 2013

\begin{tabular}{lllrlc}
\hline Sociodemographic factors & $\mathbf{n}$ & Median & (IQR) & p-value* \\
\hline \multirow{2}{*}{ Age group (years) } & $<70$ & 28 & 20.2 & $(9.3-31.1)$ & 0.38 \\
& $\geq 70$ & 52 & 12.4 & $(6.2-31.1)$ & \\
Gender & Men & 50 & 18.5 & $(9.3-37.3)$ & 0.01 \\
& Momen & 30 & 12.4 & $(6.2-24.8)$ & \\
Marital status & Married & 61 & 18.5 & $(9.3-31.1)$ & 0.02 \\
Distance to hospital & $<50$ & 19 & 9.3 & $(6.2-12.4)$ & \\
(km) & $\geq 50$ & 25 & 18.5 & $(12.4-31.1)$ & 0.17 \\
Size of household & $\leq 6$ & 55 & 12.4 & $(6.2-31.1)$ & \\
Relationship to & $\geq 7$ & 27 & 9.3 & $(6.2-18.5)$ & 0.03 \\
household head & Head & 53 & 18.5 & $(12.4-31.1)$ & \\
Household & Other & 46 & 18.5 & $(9.3-43.5)$ & 0.01 \\
socioeconomic & High or Average & 14 & 12.4 & $(6.2-24.8)$ & \\
status rank & Low & 66 & 15.5 & $(12.4-31.1)$ & \multirow{2}{*}{0.62} \\
Number of assets & 1 or more & 44 & 18.5 & $(9.3-31.1)$ & \multirow{2}{*}{0.17} \\
\hline Total & None & 36 & 12.4 & $(6.2-28.0)$ & - \\
\hline
\end{tabular}

${ }^{*}$ Kruskall-Wallis used to test for a difference in willingness to pay between subgroups

IQR: inter-quartile range 
Table 3: Distribution of willingness to pay for cataract surgery of 80 people with cataract blindness and severe visual impairment across actual costs, Zamfara state, northern Nigeria 2013

\begin{tabular}{|c|c|c|c|c|c|c|}
\hline & & & & ingness to & bay (US\$) $\dagger$ & \\
\hline & & & & $\geq \$ 18.5$ & $\geq \$ 25.2$ & $\geq \$ 51.2$ \\
\hline Sociodemograph & factors & $\mathbf{n}$ & $\mathrm{n}(\%)$ & $\mathrm{n}(\%)$ & $\mathrm{n}(\%)$ & $\mathrm{n}(\%)$ \\
\hline Age group (years) & $<70$ & 28 & $11(39.3)$ & $17(60.7)$ & $10(35.7)$ & $2(10.5)$ \\
\hline & $\geq 70$ & 52 & $28(53.8)$ & $24(46.2)$ & $16(30.8)$ & 7 (11.5) \\
\hline Gender & Men & 50 & $18(36.0)^{\star \star}$ & $32(64.0)^{\star \star}$ & $20(40.0)$ & $9(18.0)^{*}$ \\
\hline & Women & 30 & $21(70.0)$ & $9(30.0)$ & $6(20.0)$ & \\
\hline Marital status & Married & 61 & $24(39.3)^{\star *}$ & $37(60.7)^{\star \star}$ & $22(36.1)$ & 9 (14.8) \\
\hline & Widowed & 19 & $15(78.9)$ & $4(21.1)$ & $4(21.1)$ & 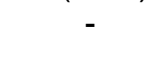 \\
\hline Distance to hospital & $<50$ & 25 & $10(40.0)$ & $15(60.0)$ & $9(36.0)$ & $1(4.0)$ \\
\hline & $\geq 50$ & 55 & $29(52.7)$ & $26(47.3)$ & $17(30.9)$ & 8 (14.5) \\
\hline Size of household & $\leq 6$ & 27 & $19(70.4)^{\star \star}$ & $8(29.6)^{\star \star}$ & $6(22.2)$ & $4(14.8)$ \\
\hline & $\geq 7$ & 53 & $20(37.7)$ & $33(62.3)$ & $20(37.7)$ & $5(9.4)$ \\
\hline Relationship to & Head & 46 & $16(34.8)$ & $30(65.2)$ & $19(41.3)$ & $9(19.6)^{\star \star}$ \\
\hline household head & Other & 34 & $23(67.6)$ & $11(32.4)$ & 7 (20.6) & - \\
\hline Household & High or & & & & & \\
\hline $\begin{array}{l}\text { socioeconomic } \\
\text { status rank }\end{array}$ & Average & 14 & $6(42.9)$ & 8 (57.1) & $5(35.7)$ & $1(7.1)$ \\
\hline status rank & Low & 66 & $33(50.0)$ & $33(50.0)$ & $21(31.8)$ & 8 (12.1) \\
\hline Number of assets & 1 or more & 44 & $18(40.9)$ & $26(59.1)$ & $17(38.6)$ & $6(13.6)$ \\
\hline & None & 36 & $21(58.3)$ & $15(41.7)$ & $9(25.0)$ & $3(8.3)$ \\
\hline Total & & 80 & $39(48.8)$ & $41(51.3)$ & $26(32.5)$ & $9(11.3)$ \\
\hline
\end{tabular}

$\dagger \$ 18.5=$ subsidised cost of surgery; $\$ 25.2=$ =median direct non-medical costs; $\$ 51.2=$ median total direct cost. ${ }^{8}$

${ }^{*} \mathrm{P}<0.05{ }^{* *} \mathrm{P}<0.01, \chi^{2}$ test of difference in source of funds between subgroups. 
Table 4: Source of funds to pay for cataract surgery among 80 people with cataract blindness or severe visual impairment, Zamfara state, northern Nigeria 2013

\begin{tabular}{|c|c|c|c|c|c|c|}
\hline \multicolumn{2}{|c|}{ Sociodemographic factors } & \multirow{2}{*}{$\begin{array}{c}\text { Total† } \\
26 \\
52\end{array}$} & \multirow{2}{*}{$\begin{array}{c}\text { Had the } \\
\text { money }\end{array}$} & \multirow{2}{*}{$\begin{array}{c}\begin{array}{c}\text { Familyl } \\
\text { friends }\end{array} \\
14(53.8) \\
36(69.2)\end{array}$} & \multirow{2}{*}{$\begin{array}{c}\begin{array}{c}\text { Sell } \\
\text { posses } \\
\text { sions }\end{array} \\
10(38.5) \\
10(19.2)\end{array}$} & \multirow{2}{*}{$\begin{array}{c}\begin{array}{c}\text { Don't } \\
\text { know }\end{array} \\
- \\
2(3.8)\end{array}$} \\
\hline Age group (years) & $\begin{array}{l}<70 \\
\geq 70\end{array}$ & & & & & \\
\hline Gender & $\begin{array}{l}\text { Men } \\
\text { Women }\end{array}$ & $\begin{array}{l}49 \\
29\end{array}$ & $\begin{array}{l}4(8.2) \\
2(6.9)\end{array}$ & $\begin{array}{l}31(63.3) \\
19(65.5)\end{array}$ & $\begin{array}{l}13(26.5) \\
7(24.1)\end{array}$ & $\begin{array}{l}1(2.0) \\
1(3.4)\end{array}$ \\
\hline Marital status & $\begin{array}{l}\text { Married } \\
\text { Widowed }\end{array}$ & $\begin{array}{l}59 \\
19\end{array}$ & $\begin{array}{l}4(6.8) \\
2(10.5)\end{array}$ & $\begin{array}{l}40(67.8) \\
10(52.6)\end{array}$ & $\begin{array}{c}15(25.4) \\
5(26.3)\end{array}$ & $2(10.5)$ \\
\hline $\begin{array}{l}\text { Distance to hospital } \\
\quad(\mathrm{km})\end{array}$ & $\begin{array}{l}<50 \\
\geq 50\end{array}$ & $\begin{array}{l}25 \\
53\end{array}$ & $\begin{array}{l}1(4.0) \\
5(9.4)\end{array}$ & $\begin{array}{l}18(72.0) \\
32(60.4)\end{array}$ & $\begin{array}{c}6(24.0) \\
14(26.4)\end{array}$ & $2(3.8)$ \\
\hline Size of household & $\begin{array}{l}\leq 6 \\
\geq 7\end{array}$ & $\begin{array}{l}27 \\
51\end{array}$ & $\begin{array}{l}1(3.7) \\
5(9.8)\end{array}$ & $\begin{array}{l}21(77.8)^{\star} \\
29(56.9)\end{array}$ & $\begin{array}{c}4(14.8) \\
16(31.4)\end{array}$ & $\begin{array}{l}1(3.7) \\
1(2.0)\end{array}$ \\
\hline $\begin{array}{l}\text { Relationship to } \\
\text { household head }\end{array}$ & $\begin{array}{l}\text { Head } \\
\text { Other }\end{array}$ & $\begin{array}{l}45 \\
33\end{array}$ & $\begin{array}{l}4(8.9) \\
2(6.1)\end{array}$ & $\begin{array}{l}29(64.4) \\
21(63.6)\end{array}$ & $\begin{array}{c}12(26.7) \\
8(24.2)\end{array}$ & $2(6.1)$ \\
\hline $\begin{array}{l}\text { Household } \\
\text { socioeconomic } \\
\text { status rank }\end{array}$ & $\begin{array}{l}\text { High or } \\
\text { Average } \\
\text { Low }\end{array}$ & $\begin{array}{l}14 \\
64\end{array}$ & $\begin{array}{l}2(14.3) \\
4(6.3)\end{array}$ & $\begin{array}{c}6(42.9) \\
44(68.8)\end{array}$ & $\begin{array}{c}6(42.9) \\
14(21.9)\end{array}$ & $2(3.1)$ \\
\hline Number of assets & $\begin{array}{l}1 \text { or more } \\
\text { None }\end{array}$ & $\begin{array}{l}43 \\
35\end{array}$ & $\begin{array}{l}4(9.3) \\
2(5.7)\end{array}$ & $\begin{array}{l}26(60.5) \\
24(68.6)\end{array}$ & $\begin{array}{c}13(30.2) \\
7(20.0)\end{array}$ & $2(5.7)$ \\
\hline Total & & 78 & $6(7.7)$ & $50(64.1)$ & $20(25.6)$ & $2(2.6)$ \\
\hline
\end{tabular}

†2 missing values

${ }^{*} \mathrm{P}<0.05, \chi^{2}$ test of difference in source of funds between subgroups. 